\title{
Assessing the Need for Applying Multimodal Speed Distribution in Road Transport Macro Emission Estimation
}

\author{
Á. Török, M. M. Zefreh \\ Budapest University of Technology and Economics, Department of Transport \\ Technology and Economics, Muegyetem rkp 3., Budapest, Hungary \\ Phone: +36 209932010 \\ e-mail: atorok@kgazd.bme.hu
}

Abstract: Vehicles speed distribution is an important input parameter in lots of issues, such as kinematical traffic simulation model, road design, speed limit evaluation, road traffic noise prediction or vehicles emission estimation. In this paper, a new approach has been presented in which the speed is randomly generated according to different speed distributions. Later on, these distributions were used as the basis of emission estimation. These different distributions were chosen according to the contextual traffic situation (free flow, pulsed accelerated flow, intersection, congestion, etc.) and were assigned to the fundamental diagram. The study of the effect of different speed distributions on the resulting emission level has been performed. The considerable difference in the emission models related to Log-normal distribution as well as exponential, chi-square and equal distribution to normal Gaussian distribution implies that these different traffic conditions will have a considerable effect on emission and will show the need for applying multimodal speed distribution in macro emission estimation rather than unimodal distribution. It should also be mentioned that this result may lead to the chance of revising the simulation software in further studies.

Keywords: speed distribution, emission models, fundamental diagram

\section{Introduction}

Speed is the fundamental measure of traffic performance of a road transport. It indicates the quality of service experienced by the users. Many researchers have put effort for modelling speed either for the homogeneous or heterogeneous traffic conditions [1-12]. The development of mathematical tools focused on the modelling of the speed distribution in a traffic flow is widely reported in the scientific literature [13-16]. Many papers concern this problem since vehicles speed distribution is an important input parameter in lots of issues, such as kinematical traffic simulation model, road design, speed limit evaluation, road traffic noise prediction, traffic safety evaluation, bicycle 
performance evaluation, analysis of pedestrian walking [17-24] etc. Since 1940 majority of papers considered speed distribution as Gaussian or Normal distribution [25] and only extreme situations are considered as the traffic volume exceeds the practical road capacity, the speed distribution may become so heavily skewed toward the higher speeds that all semblance of normality is lost. There is a lot of research that has examined distribution models for motorized vehicle speed data, such as normal distribution, skewed distribution, and composite distribution. In regard to normal distribution, Leong (1968) and McLean (1978) found that, for lightly trafficked two-lane roads where most vehicles are traveling freely, car speeds measured in time are approximately normally distributed with a coefficient of variation ranging from about $0.11-0.18[26,1]$. Minh et al. (2005) have studied that the speed distribution followed the normal distribution on the urban road [27]. Wang et al. (2012) introduced truncated normal and lognormal distribution for modeling speeds and travel time [28]. Zou (2013) proposed that skew-t distribution can reasonably take into account the heterogeneity in vehicle speed data [29]. Zou and Zhang (2011) said that a single normal distribution cannot accurately accommodate the excess kurtosis present in the speed distribution and they proposed skew normal and skew- $t$ distribution to fit speed data. They suggested that these two distributions can be applied effectively for both homogeneous and heterogeneous traffic [30]. Haight and Mosher (1962), considered that the speed data could be well represented by either a gamma or a log-normal distribution [31]. Gerlough and Huber (1975) proposed the use of the lognormal distribution. This resembles the normal distribution but is skewed with a larger tail to the right. These distributions offer the advantage that the same functional form is retained when the time speed distribution is transformed into a space-speed distribution and avoid the theoretical difficulty of the negative speeds given by the infinite tails of the normal distribution [32]. Iannone et al. (2013) assumed that a reasonable choice for the pulsed accelerated flow is the Beta distribution while the Chi-Square is proposed for the decelerated flow simulation [17]. This assumption is supported by Harmonoise (2004), where different speed distributions are related to different traffic situations [33]. Jun (2010) examined speed distribution under mixed traffic condition. He suggested, during heavy congestion speed data shows bimodality which cannot be represented by a single distribution, two different Gaussian mixture model will be required, one mixture component representing low-speed regime and another for high speed [34]. Overall some roadway sections may have more than two modes, e.g., uncongested speed range, interim speed range which lies between uncongested and congested conditions, and congested speed range. The change between unimodal speed distribution and bimodal speed distribution will indicate the pattern of traffic variations of specific interstate freeway systems [35].

Modern traffic simulation softwares are also using Gaussian normal distribution for traffic speed estimation and also have built-in emission estimation models [36]. Therefore, the connection between the distribution of speeds and emission is of great importance in this case. Around the world road traffic is the dominant anthropogenic source of air pollution in urban areas [37]. Several cities in Europe are facing traffic congestion problem daily in a critical level. Traffic congestion is known to exacerbate emissions from mobile sources in urban areas, thus contributing to air quality deterioration with significant health, environmental and economic impacts [38]. Emission tests on modern cars with advanced emission control systems [39] have demonstrated that their emissions are particularly sensitive to the occurrence of congestion in the driving 
cycle. In this situation, the motor vehicles such as passenger cars and motorcycles have made zigzag maneuvers disturbing the travel speed [40] and behaviours that are insufficient for the mentioned traffic condition. Therefore, the motor vehicles emission may change from homogeneous situations to heterogeneous conditions. The main aim of the current research is to study the effect of different speed distributions on the resulting emission level and assessing whether it is required to apply multimodal speed distribution in road macro emission estimation or not. This paper is organized as follows. Section 2 describes the way how the generated random speeds were disaggregated in order to be assigned to each and every vehicle as well as the connection between speed distributions and the fundamental diagram. Section 3 presents the results and the outputs of different velocity distributions based on fundamental diagram and analyzes the speed related emission distributions. Finally, Section 4 summarizes the conclusions.

\section{Methodology}

Speed distribution models are useful in the development of traffic simulation model for vehicle emission predictions [41]. For analysing the multimodal speed distributions and its emission estimation, a theoretical path has been investigated in this research. The average speed, number of vehicles and the speed distribution are given as an assumption. After generating the random speeds based on different speed distributions, the generated speeds have been disaggregated in order to be assigned to each and every vehicle. The velocity disaggregation for all of the speed distributions was done by programming the macro environment of Microsoft Excel software as shown in Figure 1.

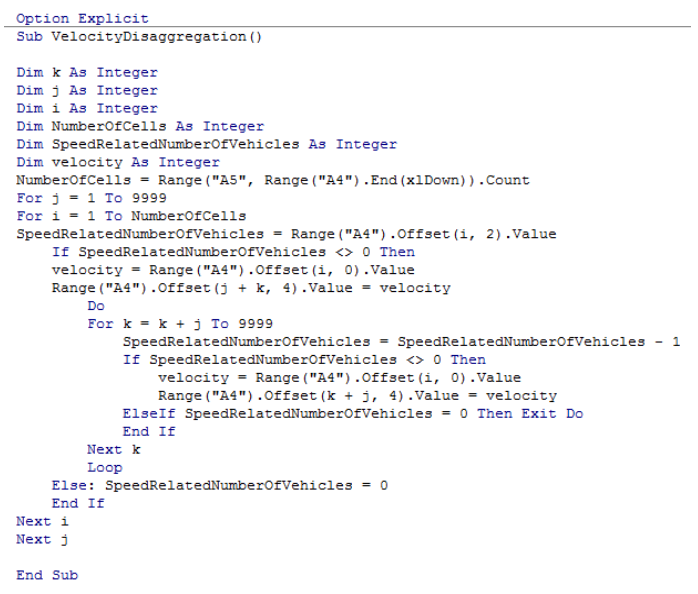

Figure 1. Velocity disaggregation command line in the macro environment of MS Excel software.

In this paper different unimodal speed distributions were combined according to different traffic conditions (congested condition or uncongested condition) and have been merged according to the dominant traffic conditions. The unimodal distributions have been shown in Figure 2. 

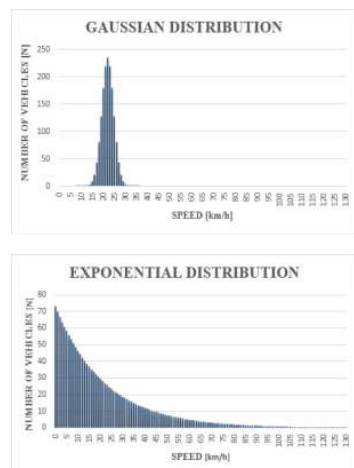

POISSON DISTRIBUTION
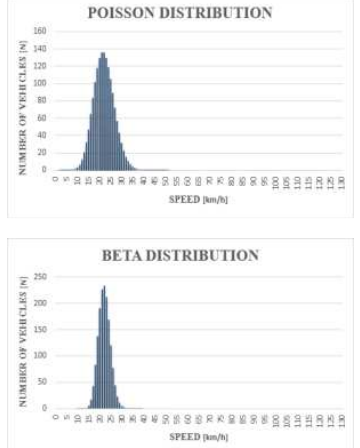

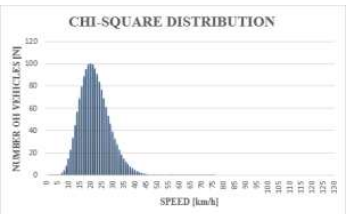

GAMMA DISTRIBUTION

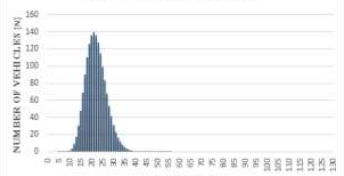

SPEED Rim/hi

T-DISTRIBUTION

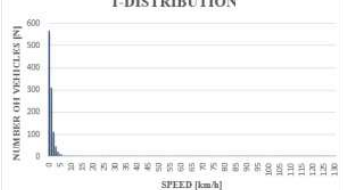

STED lanen

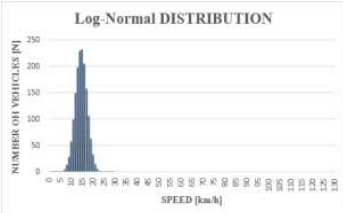

Figure 2. Investigated distributions.

By assigning speeds to every single vehicle, their related emission was determined based on different speed distributions using so-called average speed emission models. Average speed emission models, like MOBILE [42], EMFAC [43], COPERT [44] and others (e.g. [45]), are regularly applied in practice. In these models, emission factors ( $g$ $\mathrm{km}^{-1}$ ) are stated as a function of average speed. Traffic situation models use discrete emission factors $\left(\mathrm{g} \mathrm{km}^{-1}\right)$ for certain traffic situations, which can be defined in terms of a textual description (e.g. [46]) or by a set of quantitative variables (e.g. [47]).

In this paper, the authors focus on the different probability distributions that can be assigned to the fundamental diagram, depending on the traffic flow conditions (Figure 3.). Authors considered multimodal distribution as a linear combination of unimodal distributions. If the traffic conditions are not homogeneous, the normal distribution is not well suitable anymore. 


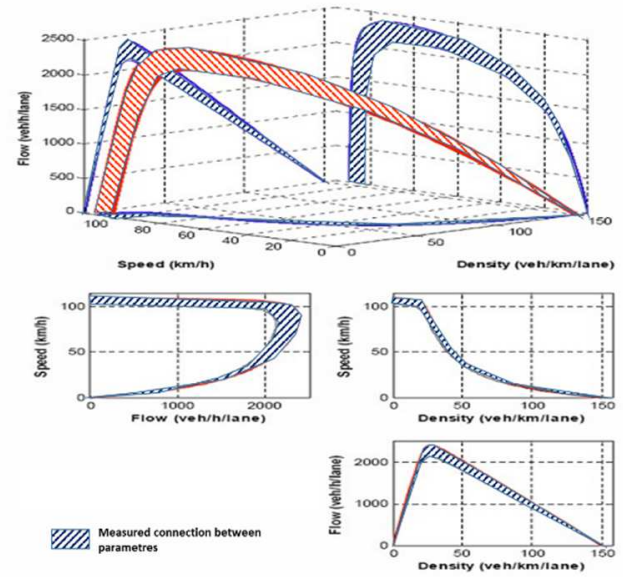

Figure 3. Sample Traffic Stream Model Variation [48].

The conditions that turn to a different speed distribution are quite often realized in nonhighway or urban roads, where, in general, the traffic stream is much more complicated. This large spread of typologies, together with other parameters such as the presence of traffic lights and the road surface conditions, leads to a significant deviation of the speed distribution curve from the generally accepted unimodal normal distribution [17].

Nowadays, many emission estimation models have been developed around the world considering more and more parameters related to road transport specialities of different countries. All these models started from a statistical approach to the emission estimation that generally does not take into account any terms regarding speed distribution only constant fuel consumption. More recent models, starting from a more precise classification into several categories (basically in Europe the EURO environmental emission categories are considered), improve the accuracy of predictions. Nowadays one of the most important developments that should be considered in these models is the dependence on the speed. Of course, one could think to overcome this problem by performing a measurement campaign (huge investment and huge effort), but the development of a new model, based on a microscopic approach with laboratory tests, able to describe every kind of traffic condition, results to be an interesting challenge.

\section{Results}

Based on literature review different unimodal speed distributions were located on the fundamental diagram. The overlap of distribution possibilities has been indicated as well (Figure 4.). Considering aforementioned, the proper combination of unimodal distributions could be reached. This combined multimodal speed distribution function could be used as a basis of Monte Carlo simulation to lower the error between real-life traffic conditions and simulation. 

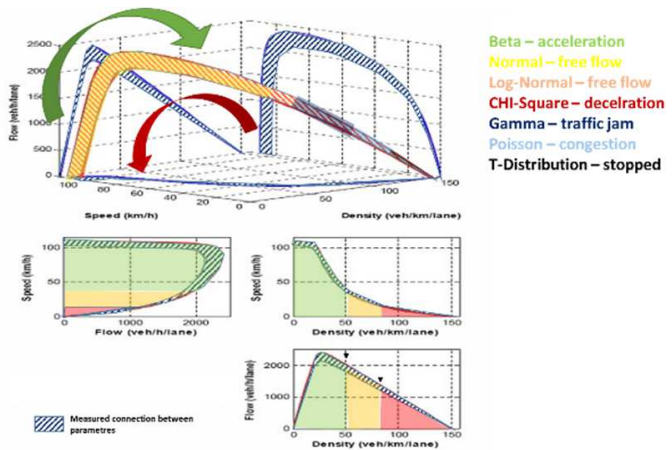

Figure 4. Investigated speed distributions on the fundamental diagram. (Own edition based on [48])

Macro emission estimation of road traffic was conducted using speed based emission estimation. Authors would like to draw one attention that significant differences were found in emission results based on different speed distributions. Taking this fact into account, error level could be even lowered by applying combined multimodal speed distribution function.

The comparison of these unimodal discrete emission distributions is shown in Figure 5.

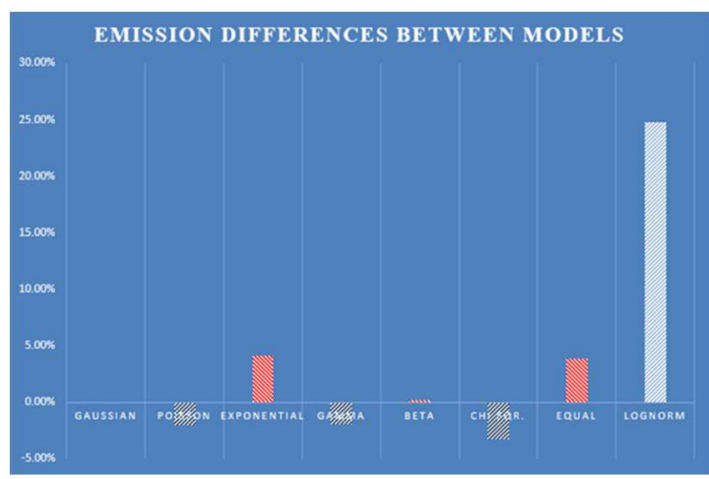

Figure 5. Differences between unimodal discrete emission models.

By taking a wide look at Figure 6, it could be expected that the more precise distribution modelling would be useful and would cause significant differences in microsimulation and emission modelling. It should be stressed that this significant difference makes necessary the usage of complex multimodal speed distribution.

\section{Conclusion}

In this paper, the authors introduced the speed distribution of the vehicular traffic flow in the evaluation of emission modelling. Any emission modelling made by unimodal 
speed distribution will not fulfil the standard traffic conditions. By introducing the dependence of speed curve profiles, the authors developed a more realistic prediction tool, able to consider the intrinsic stochastic feature of traffic phenomenon. The study of the influence of different distributions on the resulting emission level has been performed. This result leads to the chance of revising the simulation software in further studies. The considerable difference in the emission models related to Log-normal distribution as well as exponential, chi-square and equal distribution to normal Gaussian distribution implies that these different traffic conditions will have a considerable effect on emission.

\section{References}

[1] McLean J. R. (1978): Observed Speed Distributions and Rural Road Traffic Operations. 9th Australian Road Research Board Conference Proceedings., Part 5, Australian Road Research Board, Vermont South, Victoria, Australia, 235244.

[2] Katti B.K., Shastri A., Pathak R.H. (1988): Free Constrained and bunching Vehicular Flow on Urban Arterials Under Mixed Traffic Conditions. Highway Research Bulletin No. 33, Traffic Eng., Indian Roads Congress, pp. 01-14.

[3] Shankar V., Mannering F., (1998): Modeling the Endogeneity of Lane-Mean Speeds and Lane-Speed Deviations: A Structural Equations Approach. Transportation Research Part A, 32(5):311-322.

[4] Dixon K. K., Wu C.H., Sarasua W., Daniel J. (1999): Posted and Free-Flow Speeds for Rural Multilane Highways in Georgia. Journal of Transportation Engineering, ASCE, 125(6):487-494.

[5] McFadden J., Yang W., Durrans S. R. (2001): Application of Artificial Neural Networks to Predict Speeds on Two-Lane Rural Highways. Transportation Research Record 1751, Transportation Research Board, Washington, D.C., 917.

[6] Figueroa A., Tarko A. (2004): Reconciling Speed Limits with Design Speeds. HWA/IN/JTRP-2004/26, Purdue Univ., West Lafayette, Ind.

[7] Ali A., Flannery A., and Venigalla M., (2007): Preciction Models for Free Flow Speed on Urban Streets. 86th Annual Meeting of the Transportation Research Board.

[8] Himes, S. C., Donnel E.T., (2010): Speed Prediction Models for Multi-Lane Highways: A Simultaneous Equations Approach. Journal of Transportation Engineering, ASCE, 136(10)855-862.

[9] Munawar A., (2011): Speed and Capacity for Urban Roads, Indonesian Experience. 6th International Symposium on Highway Capacity and Quality of Service, Stockholm, Sweden.

[10] Dhamaniya A., Satish C., (2013): Speed Prediction Models for Urban Arterials Under Mixed Traffic Conditions. Procedia - Social and Behavioral Sciences 104(12):342-51. doi:10.1016/j.sbspro.2013.11.127.

[11] Tettamanti T., Milacski Á. Z., Lőrincz A., Varga I. (2015): Iterative Calibration Method for Microscopic Road Traffic Simulators. Periodica Polytechnica Transportation Engineering, 43(2):87-91, DOI: 10.3311/PPtr.7685 
[12] Rao A. M., Rao K. R. (2015): Free Speed Modeling for Urban Arterials - A Case Study on Delhi. Periodica Polytechnica Transportation Engineering, (ahead-ofprint). DOI: 10.3311/PPtr.7599

[13] Castro M., Sanchez J.A., Vaquero C.M., Iglesias L., Rodriguez-Solano R., (2008), Automated GIS-based system for speed estimation and highway safety evaluation, Journal of Computing in Civil Engineering, 22, 325-331.

[14] Dey P.P., Chandra S., Gangopadhaya S., (2006), Speed distribution curves under mixed traffic conditions, Journal of transportation engineering, 132, 475-481.

[15] Fitzpatrick K., Carlson P.L., Wooldridge M.D., Brewer M.A., (2000), Design factors that affect driver speed on suburban arterials, Technical Report Documentation, Texas Transportation Institute, Report n. 1769-3.

[16] Trozzi C., Vaccaro R., Crocetti S., (1996), Speed frequency distribution in air pollutants emissions estimate from road traffic, Science of the Total Environment, 189/190, $181-185$.

[17] Iannone, G., Guarnaccia, C., \& Quartieri, J. (2013). Speed distribution influence in road traffic noise prediction. Environmental Engineering And Management Journal, 12(3), 493-501.

[18] Lin S, He M, Tan Y, et al. (2008). Comparison study on operating speeds of electric bicycles and bicycles: experience from field investigation in Kunming, China. Transp. Res. Record 2008; 2048: 52-59.

[19] Wang D, Zhou D, Jin S, (2015): Characteristics of mixed bicycle traffic flow on conventional bicycle path. Presented at 94th annual meeting of the transportation research board, Washington, DC, 11-15 January 2015.

[20] Vadeby, A., Forsman A. (2014): Speed Distribution and Traffic Safety Measures. In Transport Research Arena (TRA) 5th Conference: Transport Solutions from Research to Deployment. http://tra2014.traconference.eu/papers/pdfs/TRA2014_Fpaper_18042.pdf.

[21] Maurya, A.K., Dey S., and Das S. (2015): "Speed and Time Headway Distribution under Mixed Traffic Condition.” Accessed November 22.

[22] Hustim, M. Fujimoto, K. (2012): Road Traffic Noise under Heterogeneous Traffic Condition in Makassar City, Indonesia. Journal of Habitat Engineering and Design, 4(1), 109-118.

[23] Aly B., Ramli S.H., Sumi, M.I.T. (2012): Driving Cycle of Passenger Cars on Heterogeneous Traffic Situations: Case Study on an Urban Road in Makassar, Indonesia. Proceeding of the 8th International Symposium on Lowland Technology.

[24] Chandra S., Bharti K.A. (2013): "Speed Distribution Curves for Pedestrians During Walking and Crossing." Procedia - Social and Behavioral Sciences 104 (December): 660-67. doi:10.1016/j.sbspro.2013.11.160.

[25] Loutzenheiser, D. W., \& Greenshields, B. D. (1941). Percentile Speeds on Existing Highway Tangents. In Highway Research Board Proceedings (Vol. 20).

[26] Leong HJW (1968):. The distribution and trend of free speeds on two-lane twoway rural highways in New South Wales. In: Proceedings of the 4th Australian road research board conference, part 1, Melbourne, VIC, Australia, 14-16 October 1968, pp.791-808. Vermont South, VIC, Australia: Australian Road Research Board. 
[27] Minh, C. C., Sano, K., and Matsumoto, S. (2005): The speed, Flow and Headway Analyses of Motorcucle Traffic. Journal of the Eastern Asia Society for Transportation Studies, 6, $1496-1508$.

[28] Wang, Y., Dong, W., Zhang, L., Chin, D., Papageorgiou, M., Rose, G., Young, W. (2012): Speed modeling and travel time estimation based on truncated normal and lognormal distributions. Journal of the Transportation Research Board, No. 2315, 66-72.

[29]Zou, Y. (2013): A Multivariate Analysis of Freeway Speed and Headway Data. Texas A\&M Transportation Institute.

[30]Zou, Y., and Zhang, Y. (2011) Use of Skew-Normal and Skew-t Distributions for Mixture Modeling of Freeway Speed Data. Journal of the Transportation Research Board, No. 2260, 67-75.

[31] Haight F.A., Mosher W.W., (1962), A practical method of improving the accuracy of vehicular speed distribution measurements, HRR 341, Highway Research Board, Washington, D.C., 92116.

[32] Gerlough DL and Huber MJ. Traffic flow theory: a monograph. Special report 165. Washington, DC: Transportation Research Board, National Research Council, June, 1975.

[33] Harmonoise, (2004), Imagine project funded by EC under the sixth framework program, On line at: http://www.imagine-project.org.

[34] JUN, J. 2010. Understanding the variability of speed distributions under mixed traffic conditions caused by holiday traffic. Transportation Research Part CEmerging Technologies, 18, 599-610.

[35] Ko, J., Guensler R. L. (2005): “Characterization of Congestion Based on Speed Distribution: A Statistical Approach Using Gaussian Mixture Model." In Transportation Research Board Annual Meeting. Citeseer.

[36] Batterman, S., Zhang, K., \& Kononowech, R. (2010). Prediction and analysis of near-road concentrations using a reduced-form emission/dispersion model. Environmental Health, 9, 29.

[37] Fenger, J., (1999): Urban air quality. Atmospheric Environment 33, 4877-4900.

[38] Smit R., Brown Al., Chan Y.C. (2008), Do air pollution emissions and fuel consumption models for roadways include the effects of congestion in the roadway traffic flow? Environmental Modelling and Software 23, pp.12621270.

[39]DoTRS, 2001. Comparative Vehicle Emissions Study. Commonwealth Department of Transport and Regional Services, Canberra, Australia, ISBN 0 642456844.

[40] Maghrour Zefreh, M., Torok, A., Mandoki, P., Toth, J. (2015): Maneuvers analysis of shared taxi and their effects on flow characteristics, MT-ITS Conference, Budapest June 2-5. 2015, pp328-331.

[41]Hustim, M. R., Isran M. (2013): "The Vehicle Speed Distribution on Heterogeneous Traffic: Space Mean Speed Analysis of Light Vehicles and Motorcycles in Makassar-Indonesia." In . The Eastern Asia Society for Transportation Studies. http://repository.unhas.ac.id/handle/123456789/5948

[42]USEPA, 2007. MOBILE 6 Vehicle Emission Modelling Software and Documentation. US Environmental Protection Agency, Washington, DC. http://www.epa.gov/ otaq/m6.htm. 
[43]CARB, 2002. EMFAC 2002, California Air Resources Board's Emission Inventory Series, September. http://www.arb.ca.gov//msei/onroad/latest version.htm.

[44]EEA, 2000. COPERT III Computer Programme to Calculate Emissions From Road Transport - Methodology and Emissions Factors (Version 2.1). In: Ntziachristos, L., Samaras, Z., Eggleston, S., Gorissen, N., Hassel, D., Hickman, A.-J., Joumard, R., Rijkeboer, R., White, L., Zierock, K.-H. (Eds.), November 2000, Technical Report No. 49. European Environment Agency, Copenhagen.

[45] Namdeo, A., Mitchell, G., Dixon, R., (2002): TEMMS: an integrated package for modelling and mapping urban traffic emissions and air quality. Environmental Modelling \& Software 17(2):179-190.

[46]INFRAS, 2007. Handbook Emission Factors for Road Transport - HBEFA. http://www. hbefa.net/.

[47]TNO, 2001. Emissions and Congestion - Estimation of Emissions on Road Sections and the Dutch Motorway Network. In: Gense, N.L.J., Wilmink, I.R., Van de Burgwal, H.C. (Eds.), Report No. 01.OR.VM.0441/NG. TNO Automotive, The Netherlands.

[48] Rakha, H., Farzaneh, M., Arafeh, M., Hranac, R., Sterzin, E. and Krechmer, D. (2007): Empirical Studies on Traffic Flow in Inclement Weather, Final Report Phase I. 